\title{
TRAFFIC MANAGEMENT SOLUTIONS AT ROADWORK ZONES DURING PLANNED SPECIAL EVENTS
}

\author{
DOVYDAS SKRODENIS ${ }^{1 *}$, DONATAS ČYGAS ${ }^{2}$, \\ ALGIS PAKALNIS ${ }^{1,4}$, ANDRIUS KAIRYS ${ }^{3}$ \\ ${ }^{1}$ Road Research Institute, Vilnius Gediminas Technical University, \\ Vilnius, Lithuania \\ ${ }^{2}$ Road Department, Vilnius Gediminas Technical University, Vilnius, Lithuania \\ ${ }^{3}$ Transport Competence Agency, Kaunas, Lithuania \\ ${ }^{4}$ Faculty of Mechanical Engineering and Design, \\ Kaunas University of Technology, Kaunas, Lithuania
}

Received 27 February 2020; accepted 21 December 2020

\begin{abstract}
Planned special events (PSEs) attract more people than usual to specific areas, which leads to increased traffic flows and congestions on the roads. Roadwork zones are among the most vulnerable areas on the roads, where increased traffic can lead to congestion. In roadwork zones, the vehicle flow capacity is already lower than in the conventional situations without roadworks, but at the time of PSEs, these zones become difficult to pass if no attention is paid to the change of the traffic management scheme. This kind of events poses many threats for road authorities, thus, new traffic management systems should be considered. This paper analyzes 2 PSEs and one national
\end{abstract}

* Corresponding author. E-mail: dovydas.skrodenis@vilniustech.lt

Dovydas SKRODENIS (ORCID ID 0000-0002-7120-3724)

Donatas ČYGAS (ORCID ID 0000-0001-5789-1981)

Algis PAKALNIS (ORCID ID 0000-0002-5906-8531)

Andrius KAIRYS (ORCID ID 0000-0002-4273-8463) 
celebration in Lithuania and a significant impact they have on the regular traffic flow. PSEs are taken into consideration as they attract traffic to a known place; however, national celebrations distort traffic along all roads and it is not known exactly, which roads will be congested the most. Since roadwork zones cause congestion problems even in conventional situations, this paper presents traffic capacity calculations at these road stretches during PSEs and considers how they change depending on the traffic management scheme.

Keywords: roadwork zone, special planned events, traffic capacity, traffic congestion, traffic flows.

\section{Introduction}

Mobility has been increasing significantly in the last decades and will continue increasing (Marchesini \& Weijermars, 2010). In Lithuania, the number of light vehicle registrations increased by $12 \%$ between 2014 and 2018 and the total vehicle registrations increased by $16.48 \%$ (Lithuania Official Statistics Portal, n. d.). Road stretches that have insufficient capacity for increased traffic cause traffic congestion and delays. Traffic congestion has a negative impact on the economy since it decreases productivity and the quality of people's lives (Duivenvoorden, 2010). In addition, environmental pollution increases with increasing traffic (fuel consumption and noise contribute towards increased emissions). Special planned events (PSEs) are among the many causes which lead to traffic congestion. If an event is not well planned with regard to traffic management, it can have an adverse impact not only on participants but also non-participants (FHWA, 2003).

Timely road surface renewal interventions ensure longevity of the road and comfortable driving conditions. Maintenance of the existing road network usually implies appearance of roadwork zones where traffic lanes are closed or narrowed. Roadwork zones have a significant impact on the traffic flow, these road stretches are usually indicated as the main cause of bottlenecks causing delays. Planning road maintenance, it is crucial that the planners know the capacity of the road, which would condition selection of a definite traffic management scheme. In general, capacity manuals give good estimates of road capacity, however, there is a certain lack of knowledge about the factors, which affect roadwork zone capacity the most and how variation of these factors influences traffic capacity. Various studies indicate that there can be a large variance of the impact on capacity due to different factors, such as lane width, number of lanes closed, roadwork length, type of road, time of the day, etc. In general, there is a lack of empirical studies that focus on the differences in capacity caused by roadwork zones and specific variables. It may be explained by the fact that estimating
Traffic Management Solutions at Roadwork Zones During Planned Special Events 
capacity at roadwork zones is not the primary focus compared to traffic measurements under normal conditions. The aim of this paper is to analyze the traffic flow distribution at the time of PSEs held in Lithuania, as well as to evaluate a potential traffic capacity in roadwork zones on the basis of the developed calculation model.

\section{Literature review}

PSEs can be defined as events organized for specific celebrations, performances or gatherings held at special time and place (Bowdin et al., 2006). Special events are opportunities for the local residents or tourists to experience cultural and social activities that normally differ from those experienced in the daily life. It is known that hosting an event offers direct benefits for social development and economy of the host city, such as positive effects on personal income, employment, taxes or event revenue (Crompton, 1995). However, all these impacts can be either positive or negative. PSEs can also cause social problems, such as traffic congestion or increased crime rate (Deccio \& Baloglu, 2002). PSEs are usually held in a special place or city, for this reason municipalities or other authorities can prepare for increased traffic flows. Since the purposes of PSEs could be different, negative event-related effects could cause different harm. They may differ depending on the place where the event is held (major cities or not). Negative social effect of PSEs due to traffic congestion can impact a larger number of people regardless of whether they are interested in the event or not. Traffic congestion caused by events influences daily activities. For example, the concert of Rihanna in Johannesburg (South Africa) in October 2013 caused people to wait in traffic jams for as long as five hours, while they were trying to reach the stadium. Similarly, the concert of Robbie Williams in London in 2003 caused up to 10 mile long tailbacks on the highway A1 towards the stadium (Kwoczek et al., 2014). An interesting aspect is that the traffic due to PSEs demonstrates a quite typical behavior, having two subsequent waves of congestion (Leilei et al., 2012). The first wave is caused by the flow of people going to the event, while the second wave by the people leaving the place of event. The second wave may be even larger due to the fact that all people leave the same place at the same time. However, very little research has been done on these issues. It should also be taken into consideration that each country has different national holidays. National holiday days cause active scattering of road users all around the country and it is hard to predict the direction of traffic flow. One thing that can be predicted with a decent degree of certainty is that metropolitan residents will drive out of town during the 
festive period, which may cause massive traffic jams within the city and suburbs.

The effects of traffic congestion on traffic safety, however, are less obvious. Rietveld and Shefer (1994) suggest that congestion might have a positive effect on safety since the number of fatalities declines as speeds decrease. Although this statement seems logical, there is no much detailed research on the effects of traffic congestion on road safety. As traffic flow increases and density approaches its critical values, traffic flow is said to be unstable (Marchesini \& Weijermars, 2010). Any minor disruptions or deviations from normal traffic conditions may lead to crashes. Rear-end crashes are the most common type of accidents in traffic jams due to large differences in speed. It is important to gain a clear understanding of how traffic flow processes affect safety in order to better understand developments in traffic safety and identify possibilities for improvement (Marchesini \& Weijermars, 2010).

Motorways or highways are constructed for fast and safe transport communication between other cities to accommodate for large traffic flows. Due to certain circumstances, these roads may become hard to pass as the result of traffic congestion. In most cases, road users tend to avoid congestion and opt for alternative roads that are not adapted to high traffic volumes, and the traffic safety measures applied there are not sufficient to ensure a sudden increase in vehicle intensity (Skrodenis, 2019). Two types of traffic congestion can occur in the highways: structural or incidental (Haragos et al., 2014). Structural congestion occurs when traffic demand is higher than traffic capacity or may occur due to improper road maintenance or inappropriate traffic management, while incidental congestion is the result of occasional conditions such as a crash, bad weather or road works, which alter the traffic flow (Duivenvoorden, 2010). Cases of incidental congestion cannot be predicted and occur naturally. For many years, engineers have collected the data and analyzed various highway facility types in order to gain a thorough understanding of the concept of capacity. As a result, methods to estimate capacity were developed, but few of the methods pertained to work zones (Ortiz, 2014). Denmark has created a model that considers roadworks on motorways and rural highways with two lanes (Vejdirektoratet, 2010). According to the Danish experience, temporary short-term roadworks generally result in a lower traffic capacity than long-term roadworks. The main benefit of longterm roadworks is that drivers eventually get acquainted with the situation and this leads to a safer and more effective driver behavior (in terms of capacity). Narrow lanes have a negative impact, they lead to deterioration of normal driving conditions (Godley et al., 2004) and driving speed (Chitturi and Benekogal, 2005). Hogema and Brouwer (1999) found that narrowed traffic lanes at roadwork zones lead to less overtaking, which
Traffic Management

Solutions at Roadwork Zones

During Planned

Special Events 
means that the spacing between platoons of vehicles fill less quickly than under conventional driving conditions. This leads to the decrease of vehicle density and reduces capacity. Since the roadworks are often associated with narrow lanes, a large proportion of heavy vehicles in the flow has a considerable influence on the driving speed and capacity. Al Kaisy and Hall (2003) found that instead of the normal capacity value of $2160 \mathrm{veh} . / \mathrm{h}$ per lane, the capacity of the narrowed lanes at roadwork zones was measured to be 1800 veh./h per lane. Their study also showed a decrease of $7 \%$ to $16 \%$ in the number of commuting drivers at weekends and during off-peak hours through the roadwork zone. This suggests that daily commuters use alternative roads instead of driving through the work zone. Al Kaisy and Hall also found that different speed limits and types of separation/barriers result in different reduction of capacity in the range of $1 \%$ to $5.12 \%$. Moreover, researchers found an increase in capacity of $5 \%$ to $10 \%$ when no work or non-visible work is carried out at the roadwork zone, since road users are less distracted and can pay more attention to the driving task. Weinspach (1988) indicated that lanes less than $3.50 \mathrm{~m}$ in width result in capacity reduction of up to $15 \%$, however, in BASt (2011) the threshold was updated to $3.25 \mathrm{~m}$. There is still certain lack of knowledge on how different variables affect traffic capacity during roadworks between different situations. Only a few studies focusing on the differences in capacity caused by specific roadworks situation variables have been carried out. Some studies indicate a positive effect of increasing a roadwork zone length (Karim \& Adeli, 2003; Ullman et al., 2009), however other studies show that this variable does not affect capacity at all (Benekohal et al., 2010). Some studies indicate that lane width (Vejdirektoratet, 2010), duration of roadworks (Maze \& Bortle 2005), time of day (Benekohal et al., 2003) and location of the roadwork (Karim \& Adeli, 2003) are significant for traffic capacity calculations. Capacity can be affected not only by the known variables, but also by such unpredictable variables as rain. Literature review allows identifying the most common variables at roadwork zones. These variables are listed in the Swedish Capacity Manual, which is used to calculate traffic capacity under PSE and normal conditions at roadwork zones in Lithuania.

\section{Research methodology for capacity calculation at roadwork zones}

Several national events are held by the seaside each year in Lithuania, which attract plenty of people from all over the country. The first event considered in this research is called "Palanga Stint", it is organized 
on February 7-9th. The second event is "The Sea Festival" held on July 24-26th. Both of them happen roughly in the same place. The third event is "All Saints Day" that takes place on 1 November. This event distorts traffic all around the country, although cemeteries remain the main points of attraction of the traffic flow. The data on traffic were collected with the detectors built in the road surface, which classified vehicles by the number of axes and the length between the axes.

Work zones on freeways usually affect the quality of service available for the road users. However, during PSEs these road stretches become bottlenecks in the highways. For this reason, traffic management is crucial, especially during PSEs of national significance. Different countries use different tools and methods to predict possible traffic volume during PSEs. Traffic prediction is crucial in order to apply correct traffic management schemes for preventing bottlenecks at roadwork zones. However, any change in the traffic conditions leads to reduction in traffic at roadwork zones. The most accurate data possible must be used for the calculations in order to predict possible capacity at roadwork zones. Variables used in the calculations depend on the country, however, it is recommended to use such most important variables as roadwork length, traffic lane widths, volume of heavy and light vehicles, and the number of lanes. All these variables should be included in the calculation of passenger car unit (PCU) per hour. According to Swedish Capacity Manual (Trafikverket, 2014) and Guidelines for Effect Calculations (Trafikverket, 2015), the total flow to PCU conversion factor is calculated as

$$
f_{H V}=\frac{\alpha}{1+P_{\mathrm{T}}\left(E_{\mathrm{T}}-1\right)+P_{\mathrm{TT}}\left(E_{\mathrm{TT}}-1\right)},
$$

where $P_{\mathrm{T}}$ - proportion of trucks without trailers and buses; $P_{\mathrm{TT}}-$ proportion of trucks with trailers; $E_{\mathrm{T}}$ - passenger car units (PCU) for trucks without trailers and buses (Table 1); $E_{\mathrm{TT}}-$ PCU for trucks with trailers (Table 1); $\alpha-0.975$ for sight Class 1 and 0.94 for sight Class 2 [sight class is a type of road alignment class used in the Swedish Capacity Manual (Trafikverket, 2014, 2015)].

Table 1. Values of PCU for trucks $\left(E_{T}\right)$ and trucks with trailers $\left(E_{\mathrm{TT}}\right)$ depending on gradient

\begin{tabular}{ccc}
\hline Gradient, $\%$ & $\boldsymbol{E}_{\mathrm{T}}$ & $\boldsymbol{E}_{\mathrm{TT}}$ \\
\hline$<3$ & 1.3 & 1.7 \\
\hline $3-4$ & 2.0 & 2.6 \\
\hline$>4$ & 2.6 & 3.4 \\
\hline
\end{tabular}

Traffic Management Solutions at Roadwork Zones During Planned Special Events 
The capacity in terms of PCU/h $\left(q_{\text {cap }}\right)$ is calculated as

$$
q_{\text {cap }}=C f_{\mathrm{HV}}
$$

where $C$ - capacity according to speed-flow relationship, veh./h (Trafikverket, 2015); $f_{\mathrm{HV}}-$ PCU conversion factor calculated according to Eq. (1).

The model below created by $\mathrm{D}$ for capacity reduction at roadwork zones on motorways is based on the data and correction factors for different roadwork situation-specific variables from Germany, USA and Denmark (Strömgren \& Olstam, 2016). In the model, the reduced capacity of a lane that is continuously kept open is calculated as

$$
q_{\mathrm{Red}}^{i}=f_{\mathrm{rs}} f_{\mathrm{co}} f_{\mathrm{rnl}} f_{\mathrm{c} 50} f_{1} f_{\mathrm{lw}} q_{\mathrm{cap}},
$$

where $q_{\text {cap }}$ - capacity calculated according to Eq. (2); $f_{\text {rs }}$ - correction parameter for the closed road shoulder (Table 2); $f_{\mathrm{co}}$ - correction parameter for the crossover (Table 2); $f_{\mathrm{rnl}}$ - correction parameter for reduction of the number of lanes (Table 2); $f_{c 50}$ - correction parameter for the commuter traffic (Table 2); $f_{1}$ - correction parameter for the length of the work zone (Table 2); $f_{\mathrm{lw}}$ - correction parameter for the lane width (Table 2).

The remaining capacity $q_{\mathrm{Red}}^{i}$ is calculated for each remaining open lane where closed lanes are not counted. The correction factor for reduced capacity due to a closed road shoulder $\left(f_{\mathrm{rs}}\right)$ should only be used for the right lane. The remaining capacities of the open lanes are aggregated to a total remaining capacity as

$$
q_{\mathrm{Red}}=\sum_{i=1}^{n} q_{\mathrm{Red}}^{i}
$$

\begin{tabular}{|c|c|c|c|c|c|c|}
\hline \multirow{2}{*}{ Correction parameter } & \multirow{2}{*}{ Correction factor } & \multicolumn{5}{|c|}{ Correction factor for lane width, $m$} \\
\hline & & $\geq 3.50$ & 3.25 & 3.00 & 2.75 & 2.50 \\
\hline Closed road shoulder $\left(f_{\mathrm{rs}}\right)$ & $\begin{array}{c}0.8 \text { (0.9 in } \\
\text { combination with } \\
\text { other measures) }\end{array}$ & - & - & - & - & - \\
\hline Crossover $\left(f_{\mathrm{co}}\right)$ & 0.95 & - & - & - & - & - \\
\hline Reduction of number of lanes $\left(f_{\mathrm{rnl}}\right)$ & 0.95 & - & - & - & - & - \\
\hline Commuter traffic $<50 \%\left(f_{\mathrm{c} 50}\right)$ & 0.90 & - & - & - & - & - \\
\hline Length of roadwork zone $>2000 \mathrm{~m}\left(f_{\mathrm{l}}\right)$ & 0.95 & - & - & - & - & - \\
\hline Lane width $\left(f_{\mathrm{IW}}\right)$ & - & 1.00 & 0.95 & 0.90 & 0.85 & 0.80 \\
\hline
\end{tabular}

Table 2. Correction parameters for motorways at various roadwork zone designs (BASt, 2011; Vejdirektoratet, 2010) 
Reduction of commuting traffic should not be used for roadworks

Traffic Management Solutions with duration less than 1 to 2 weeks. Commuting traffic represents mornings and afternoons and non-commuting traffic represents other times including weekends. All correction parameters shown in Table 2 at Roadwork Zones During Planned Special Events are taken from the German Tutorial (BASt, 2011) except for $f_{1}$ and $f_{\text {lw }}$ which are taken from the Danish Capacity Manual (Vejdirektoratet, 2010). All these parameters are based on the measurements at various roadwork zones.

In addition, free flow speed calculations were taken into consideration. Average speed calculations were done using the methodology for mixed traffic and highways/freeways suggested by the Highway Capacity Manual 2016 (Transportation Research Board, 2016). Since there are many different variables in each scenario, it is recommended to use Chapter 26 of Volume 4 of the supplemental HCM document. There are many different scenarios how to calculate free flow speed, however, each calculation differs in terms of variables. In this paper, a mixed-traffic scenario was used.

\section{Results}

\subsection{Traffic distribution due to PSEs}

Detailed traffic volume analysis during "The Sea Festival" revealed that the number of vehicles towards and outward Klaipeda City increases, as shown in Figure 1.

Traffic volume towards Klaipèda increased by $11.80 \%$ in $2015,9.69 \%$ in $2016,19.33 \%$ in $2017,20.54 \%$ in 2018 and $12.37 \%$ in 2019 relative

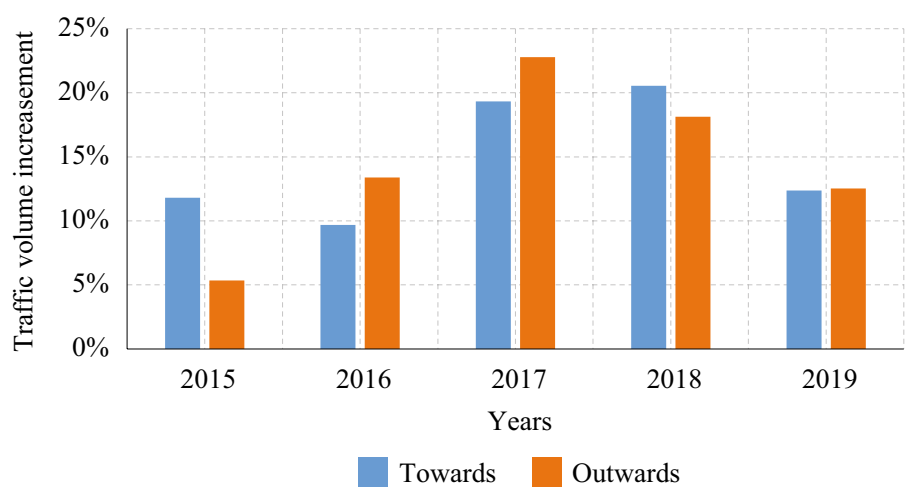

Figure 1. Traffic volume increase towards and outward Klaipeda during the PSE 
to the period when the festival is not held. The reference weekend was selected considering the periods when no established PSEs were taking place in the studied region, which could distort traffic intensity data. Since "The Sea Festival" is held during a summer weekend, the reference weekend was also selected in the summer season. Naturally, during the event, the traffic volume outward Klaipeda also increased - by $5.35 \%$ in $2015,13.38 \%$ in $2016,22.79 \%$ in $2017,18.12 \%$ in 2018 and $12.52 \%$ in 2019. These numbers prove the statement that mobility is constantly increasing.

Road A1 is a highway constructed for the main traffic flow towards and outward Klaipeda city from the capital and other big cities. However, traffic volume data from the surrounding roads revealed that road users tend to choose alternative roads (regional roads) to reach Klaipedda, especially during national events. The functional purpose of regional roads is to collect traffic from rural villages and link it to the national or main roads. However, a PSE distorts usual traffic volumes in these roads. These roads are unsuitable for high traffic flows and deviations affect the longevity of the road. Regular date stands for a basic date when no celebration or other event is held nearby. Event date stands for the date when celebration happens. "The Sea Festival" attracts by 3.72\% more

Table 3. Differences between traffic volume towards and outward Klaipèda during "The Sea Festival" and a regular weekend

\begin{tabular}{|c|c|c|c|c|c|c|}
\hline \multicolumn{7}{|c|}{ Towards Klaipèda } \\
\hline \multirow{2}{*}{ Year } & \multicolumn{6}{|c|}{ Road No. } \\
\hline & 2202 & A1 & 2215 & 2212 & 168 & 2250 \\
\hline 2015 & $-2.7 \%$ & $3.7 \%$ & $18.4 \%$ & $28.6 \%$ & $19.9 \%$ & $-2.5 \%$ \\
\hline 2016 & $6.3 \%$ & $2.1 \%$ & $23.0 \%$ & $20.1 \%$ & $-1.6 \%$ & $17.1 \%$ \\
\hline 2017 & $10.1 \%$ & $7.1 \%$ & - & $32.8 \%$ & $31.4 \%$ & $20.7 \%$ \\
\hline 2018 & $5.2 \%$ & $25.4 \%$ & $-35.4 \%$ & $31.4 \%$ & $24.9 \%$ & $11.9 \%$ \\
\hline 2019 & $-8.4 \%$ & $6.1 \%$ & $15.0 \%$ & $21.7 \%$ & $23.9 \%$ & $11.7 \%$ \\
\hline \multicolumn{7}{|c|}{ Outward Klaipèda } \\
\hline \multirow{2}{*}{ Year } & \multicolumn{6}{|c|}{ Road No. } \\
\hline & 2202 & A1 & 2215 & 2212 & 168 & 2250 \\
\hline 2015 & $-8.72 \%$ & $0.37 \%$ & $24.03 \%$ & $18.71 \%$ & $-1.70 \%$ & $-1.73 \%$ \\
\hline 2016 & $4.24 \%$ & $1.47 \%$ & $25.69 \%$ & $27.28 \%$ & $25.76 \%$ & $1.55 \%$ \\
\hline 2017 & $29.28 \%$ & $16.42 \%$ & - & $31.62 \%$ & $26.60 \%$ & $8.47 \%$ \\
\hline 2018 & $3.75 \%$ & $20.15 \%$ & $-27.73 \%$ & $29.72 \%$ & $22.18 \%$ & $11.65 \%$ \\
\hline 2019 & $-7.40 \%$ & $7.91 \%$ & $27.00 \%$ & $20.13 \%$ & $16.53 \%$ & $12.29 \%$ \\
\hline
\end{tabular}


Table 4. Differences between traffic volume towards and outward Klaipèda during "The Sea Festival" and a regular weekend considering road significance

\begin{tabular}{|c|c|c|c|c|c|c|c|c|c|c|}
\hline \multicolumn{11}{|c|}{ Towards Klaipèda } \\
\hline \multirow{3}{*}{$\begin{array}{l}\text { Road } \\
\text { significance }\end{array}$} & \multicolumn{10}{|c|}{ Years } \\
\hline & \multicolumn{2}{|c|}{2015} & \multicolumn{2}{|c|}{2016} & \multicolumn{2}{|c|}{2017} & \multicolumn{2}{|c|}{2018} & \multicolumn{2}{|c|}{2019} \\
\hline & Reg. & Event & Reg. & Event & Reg. & Event & Reg. & Event & Reg. & Event \\
\hline Main roads & $38.1 \%$ & $34.9 \%$ & $36.2 \%$ & $33.4 \%$ & $44.2 \%$ & $38.4 \%$ & $34.7 \%$ & $36.9 \%$ & $37.4 \%$ & $34.9 \%$ \\
\hline $\begin{array}{l}\text { National } \\
\text { roads }\end{array}$ & $13.7 \%$ & $15.1 \%$ & $15.2 \%$ & $13.5 \%$ & $12.2 \%$ & $14.3 \%$ & $12.7 \%$ & $13.5 \%$ & $11.6 \%$ & $13.3 \%$ \\
\hline $\begin{array}{l}\text { Regional } \\
\text { roads }\end{array}$ & $48.2 \%$ & $50.0 \%$ & $48.5 \%$ & $53.1 \%$ & $43.6 \%$ & $47.3 \%$ & $52.6 \%$ & $49.6 \%$ & $51.0 \%$ & $51.7 \%$ \\
\hline \multicolumn{11}{|c|}{ Outward Klaipėda } \\
\hline \multirow{3}{*}{$\begin{array}{c}\text { Road } \\
\text { significance }\end{array}$} & \multicolumn{10}{|c|}{ Years } \\
\hline & \multicolumn{2}{|c|}{2015} & \multicolumn{2}{|c|}{2016} & \multicolumn{2}{|c|}{2017} & \multicolumn{2}{|c|}{2018} & \multicolumn{2}{|c|}{2019} \\
\hline & Reg. & Event & Reg. & Event & Reg. & Event & Reg. & Event & Reg. & Event \\
\hline Main roads & $39.5 \%$ & $37.5 \%$ & $41.2 \%$ & $36.2 \%$ & $44.7 \%$ & $41.3 \%$ & $39.7 \%$ & $40.7 \%$ & $38.3 \%$ & $36.3 \%$ \\
\hline $\begin{array}{l}\text { National } \\
\text { roads }\end{array}$ & $14.3 \%$ & $13.3 \%$ & $12.2 \%$ & $14.2 \%$ & $14.9 \%$ & $15.7 \%$ & $14.2 \%$ & $14.9 \%$ & $13.4 \%$ & $14.1 \%$ \\
\hline $\begin{array}{l}\text { Regional } \\
\text { roads }\end{array}$ & $46.2 \%$ & $49.2 \%$ & $46.6 \%$ & $49.6 \%$ & $40.4 \%$ & $43.0 \%$ & $46.2 \%$ & $44.4 \%$ & $48.3 \%$ & $49.6 \%$ \\
\hline
\end{tabular}

vehicles each year. Table 3 presents traffic volume distribution within all roads towards and outward Klaipeda City. Table 4 presents traffic distribution considering significance of the roads. Data analysis proves that usability of regional roads increases during the event.

"Palanga Stint" is another event which attracts people to the seaside. There are two major highways leading to the city of Palanga where the event takes place. Traffic volume analysis revealed a clear increase of traffic towards and outward Palanga during the PSE. Detailed results are presented in Figure 2.

Traffic volume analysis revealed that the volume of vehicles towards Palanga increased by $29.34 \%$ in 2016, 23.85\% in 2017, 36.97\% in 2018 and $32.34 \%$ in 2019 . Outward traffic increased by $24.50 \%$ in 2016 , $28.32 \%$ in 2017, $31.10 \%$ in 2018 and $31.57 \%$ in 2019. Since "Palanga Stint" is held during a winter weekend (in February), the reference weekend taken for comparison was also selected during the winter season. Palanga City is connected by two main roads - A11 and A13, for this reason, traffic distribution by road significance has not been performed. Detailed traffic flow distribution by year is presented in Table 5. 


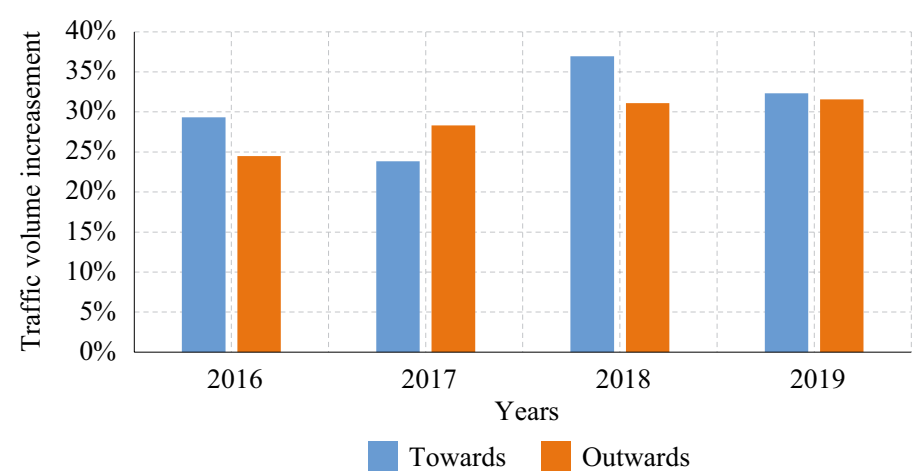

Figure 2. Traffic volume increase towards and outward Palanga during the PSE

"All Saints Day" is yet another event which distorts regular traffic flows. This is an annual event which happens on November 1st. This event is dedicated to honoring the dead, during this event, traffic flows distribute unpredictably. Some main roads around the Lithuanian capital - Vilnius - were chosen for traffic flow analysis, keeping in mind that these roads are the major commutation links between the other

Table 5. Differences between traffic volume towards and outward Palanga during "Palanga Stint" and a regular weekend

\begin{tabular}{ccc}
\hline & \multicolumn{3}{c}{ Towards Palanga } \\
& \multicolumn{3}{c}{ Road No. } \\
\cline { 2 - 3 } Year & A11 & A13 \\
\hline 2016 & $30.81 \%$ & $28.77 \%$ \\
\hline 2017 & $27.39 \%$ & $22.39 \%$ \\
\hline 2018 & $40.21 \%$ & $35.73 \%$ \\
\hline 2019 & $28.57 \%$ & $33.35 \%$ \\
\hline Year & Outward Palanga & \\
\hline 2016 & A11 & A13 \\
\hline 2017 & $26.90 \%$ & $23.47 \%$ \\
\hline 2018 & $29.16 \%$ & $27.98 \%$ \\
\hline 2019 & $33.08 \%$ & $30.30 \%$ \\
\hline
\end{tabular}


Table 6. Differences between traffic volume towards and outward Vilnius during "All Saints Day" and a regular weekend

\begin{tabular}{cccccc}
\hline \multirow{2}{*}{ Year } & \multicolumn{5}{c}{ Towards Vilnius } \\
\cline { 2 - 6 } & A1 & A2 & A4 & A14 & A16 \\
\hline 2015 & $23.4 \%$ & $23.5 \%$ & - & - & - \\
\hline 2016 & $-42.2 \%$ & $1.4 \%$ & $11.7 \%$ & $-2.7 \%$ & $-14.6 \%$ \\
\hline 2017 & $-31.7 \%$ & $15.7 \%$ & $15.8 \%$ & $4.0 \%$ & $-18.3 \%$ \\
\hline 2018 & $-7.6 \%$ & $37.4 \%$ & $28.1 \%$ & $-15.5 \%$ & $-15.0 \%$ \\
\hline 2019 & $-14.7 \%$ & $26.6 \%$ & $5.9 \%$ & $-15.0 \%$ & $-29.4 \%$ \\
\hline Year & & Outward Vilnius & & \\
\hline 2015 & $8.2 \%$ & $34.4 \%$ & Road No. & & A16 \\
\hline 2016 & $-9.8 \%$ & $40.5 \%$ & $31.5 \%$ & $19.3 \%$ & $-1.7 \%$ \\
\hline 2017 & $-29.7 \%$ & $28.9 \%$ & $23.5 \%$ & $13.6 \%$ & $-11.2 \%$ \\
\hline 2018 & $-28.9 \%$ & $25.2 \%$ & $25.2 \%$ & $-7.1 \%$ & $-10.6 \%$ \\
\hline 2019 & $-41.0 \%$ & $14.9 \%$ & $6.6 \%$ & $-10.6 \%$ & $-23.6 \%$ \\
\hline
\end{tabular}

Lithuania regions. Detailed traffic flow distribution by year and road is presented in Table 6.

Tables 3-5 present traffic flow distribution during the event and regular days. However, it is important to take into consideration that event days distort regular peak hours, which further complicates accurate prediction of the scope of increasing traffic. The data from 2019 "The Sea Festival" were used for more detailed calculations. Figure 3 illustrates data point positions that were used to collect the traffic flow data. Two data points were selected for highway A1 to make more accurate predictions how users behave during events and which roads are chosen to reach the city. The first data point was taken for hourly traffic flow calculations because it is located before the major intersection that decomposes traffic. Figures 4 and 5 present traffic flow distributions by hour towards and outward Klaipèda. Figure 4 shows clear increase in the traffic flow and how peak hours are shifted from the regular positions. The major traffic increase was detected on Friday at 8-9 pm, when traffic during the event was three times higher compared to the same hours on a regular Friday. During the event, the peak of traffic flow starts originating about noon and for several consecutive hours. Hourly traffic analysis shows that traffic flows tend to increase in
Traffic Management Solutions at Roadwork Zones During Planned Special Events 


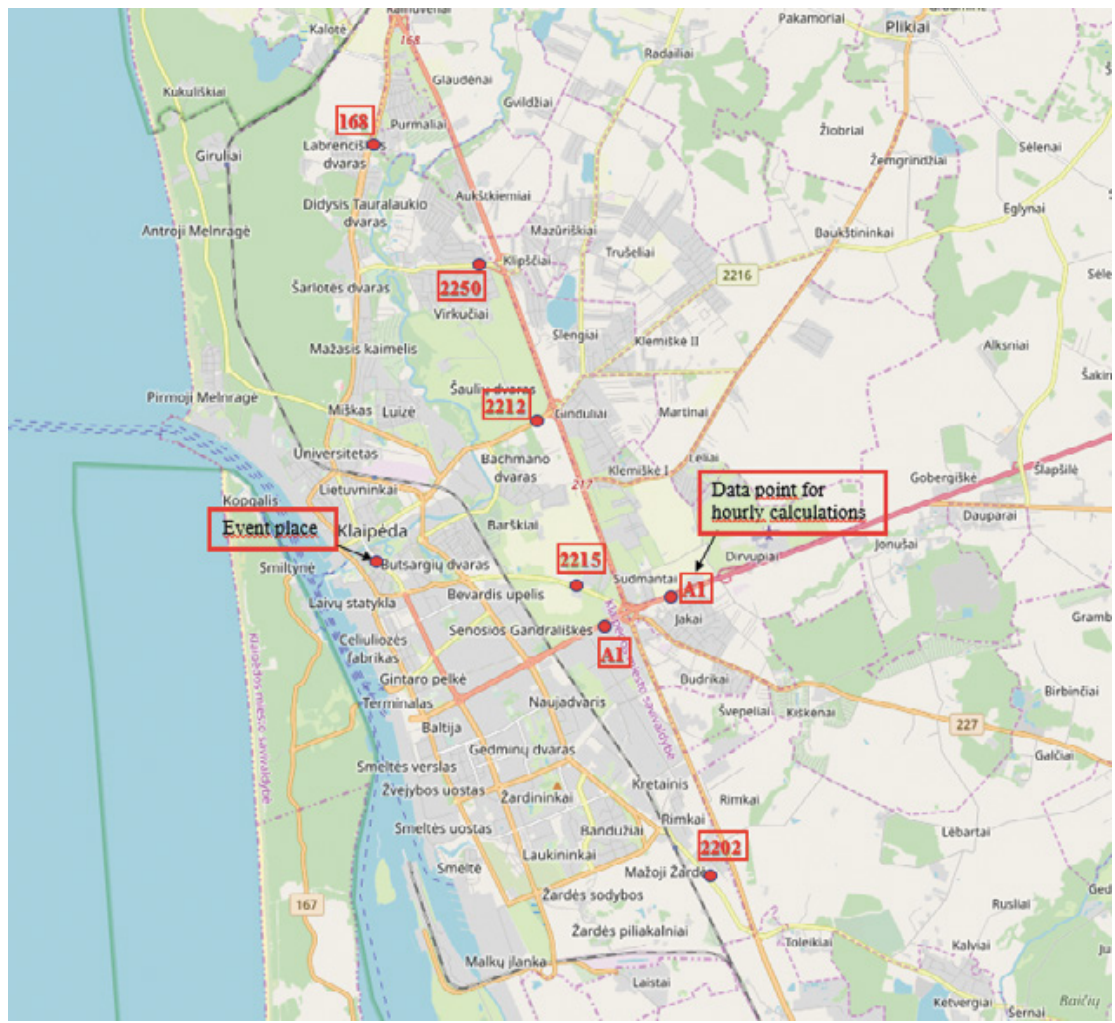

Figure 3. Data points for traffic flow volume collection

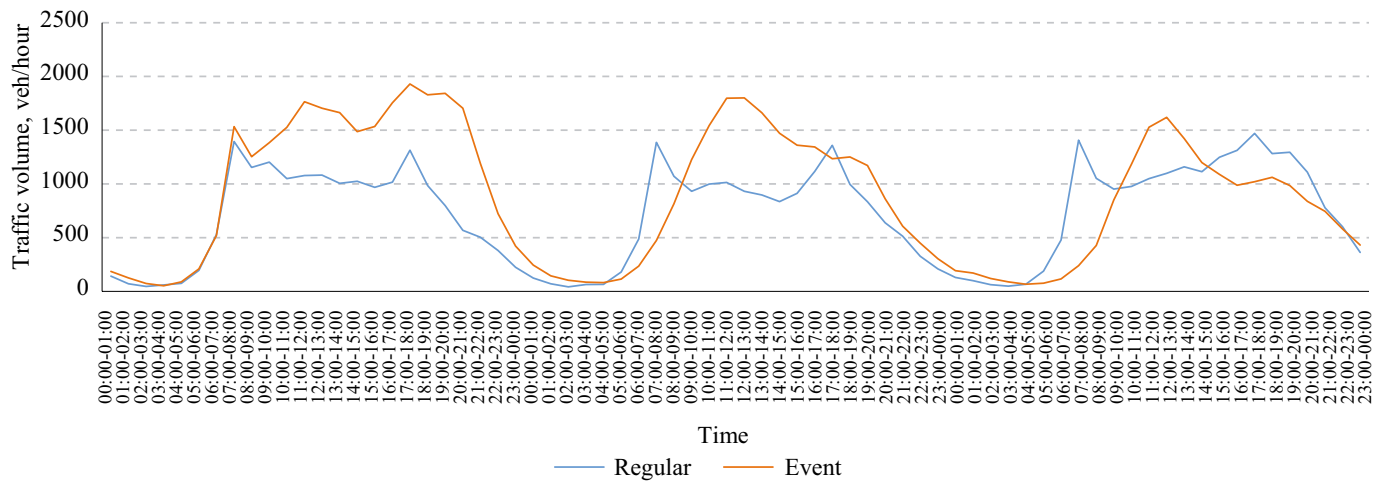

Figure 4. Distribution of traffic flow by hour towards Klaipeda during "The Sea Festival" and on a regular day 


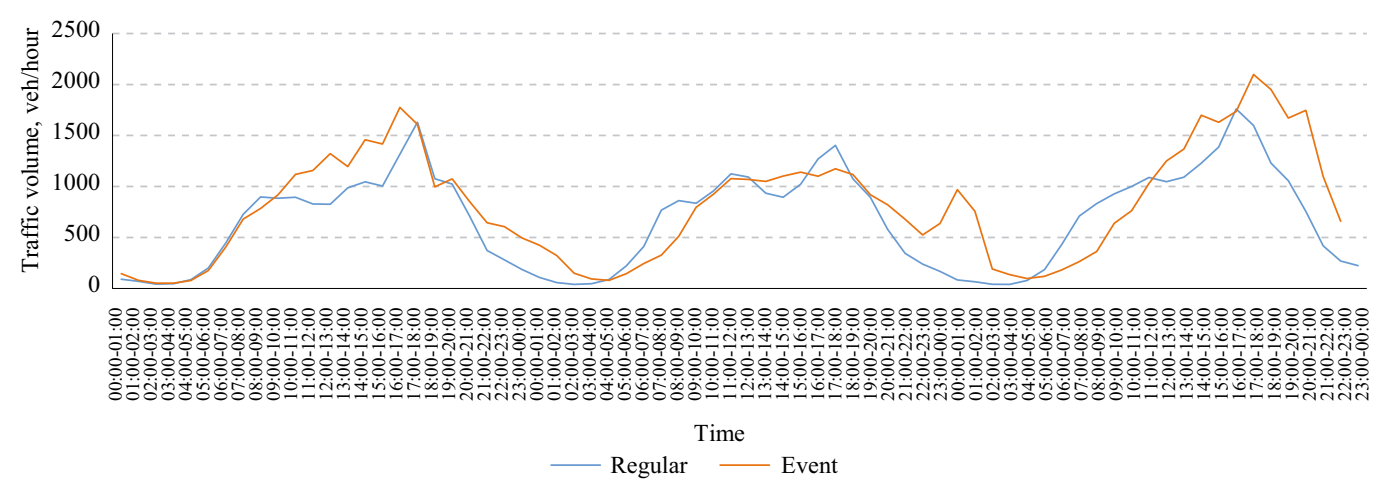

Figure 5. Distribution of traffic flow by hour outward Klaipeda during "The Sea Festival" and on a regular day

the evening of the first day of the event (Friday in this example). It takes a 2-4 hours' drive to Klaipeda City from other major cities in Lithuania, for this reason, the peak hour on Friday was 5-6 pm (straight after work hours), and the increase in traffic to Klaipeda was monitored until $11 \mathrm{pm}$. The second batch of road users reached Klaipeda on the second day of the event at 1-5 pm. The last visitors on Sunday came to Klaipeda at almost same time as on Saturday - from $1 \mathrm{pm}$ to $3 \mathrm{pm}$. Regular peak hours in Klaipeda during weekends are approximately the same as on the usual dates - morning peaks at 6-8 am and evening peaks at 4-6 pm. During the event, the maximum traffic flow was recorded in later hours and was monitored for a longer period than usual.

\subsection{Capacity calculation at roadwork zones}

Results in sub-chapter 3.1 clearly show the increase of the number of vehicles during PSEs or national events. As mentioned before, roadworks are the places where traffic congestion and bottlenecks appear. Increased traffic leads to greater congestions at roadwork zones if no changes are made to conventional traffic management schemes. This chapter describes what influence certain roadwork zones variables (merging, narrow lanes, closed lane, opening lane) have on the capacity. Results in Table 7 presents traffic flow capacity calculations for twolane highway according to Eqs. (1)-(4), but no actual research on traffic management was done during the studied PSEs or during national events.

Free flow capacity represents the maximum traffic flow without any interventions. Work zone capacities depend on the traffic management schemes, however, most common situations were considered in the 
calculations. For all calculated scenarios, work zone length was chosen as $2000 \mathrm{~m}$ or more. Two lanes scenario represents a situation when the right lane is completely closed and the standard lane $3.5 \mathrm{~m}$ in width is left for traffic. This capacity could change if works happen in the left lane. Two lanes narrowed scenario represents a situation when both traffic lanes (one way) are left for traffic, however, the lanes are narrowed to $2.5 \mathrm{~m}$ width. The detailed analysis of the hourly "The Sea Festival" case demonstrated highly increased traffic flows with max. traffic of 2100 veh./h. For this reason, both mentioned work zone schemes could not handle such high volume of traffic and new scenarios should be chosen. Two lanes + one crossover lane scenario represents a situation when both lanes (one way) are open for traffic and one more is added with a crossover. It has been found that during PSEs or national events, the number of possible roadwork zones on the roads should be reduced to the minimum or these stretches should be re-organized to handle increased traffic. Also, some prediction of routing should be made to allow road authorities to choose the best traffic management scheme or to introduce variations to improve capacity.

\section{Conclusions}

1. Roadwork zones significantly impact free traffic flows. The traffic flow decreases from $31 \%$ to $47 \%$ at the roadwork zones. The extent of this impact depends on the share of heavy vehicles and traffic management schemes at these road stretches.

2. "The Sea Festival" attracted on average by $14.70 \%$ more traffic to Klaipedda City as compared to the reference weekend. "Palanga Stint" attracted by $30.63 \%$ more road users as compared to the reference weekend. The number depends on the road and year. Detailed traffic increase numbers are presented in Figures 1 and 2.

3. "All Saints Day" distorts traffic flows since there is no one single place that attracts people. Major highway A1 is used less than on a regular weekend, however, other main roads which connect other big cities are heavily congested. Traffic flows increase from $6 \%$ to $40 \%$ depending on the road and year.

4. The reported percentage of traffic increase does not reflect the actual situation, since on a normal weekend, toward and outward traffic is more dispersed during the day.

5. Roadwork zones decrease the maximum traffic capacity by approximately $30 \%$. Capacity reduction depends on the layouts and traffic management schemes. 
6. The average traffic speed on the highways differs greatly during PSEs or national events. At the speed limit $130 \mathrm{~km} / \mathrm{h}$, the average traffic speed calculated at a regular weekend is $118 \mathrm{~km} / \mathrm{h}$, while during PSEs $-99 \mathrm{~km} / \mathrm{h}$.

7. Road authorities should consider changing traffic management plans at roadwork zones depending on directions of the traffic flow. New lanes could be opened, machinery pulled away from the driveway and all construction-related work should be stopped to prevent congestions during PSEs or national holidays. Work zone capacity calculations show that an additional lane could add extra capacity through the roadwork zone of more than $1300 \mathrm{veh} . / \mathrm{h}$. Changing the pre-timed signal cycle length should be considered and traffic flow directional flow should be taken into account in these work zones when traffic is organized through a single lane.

\section{REFERENCES}

Al-Kaisy, A., \& Hall, F. (2003). Guidelines for Estimating Capacity at Freeway Reconstruction Zones. Journal of Transportation Engineering, 129(5), 572-577. https://doi.org/10.1061/(asce)0733-947x(2003)129:5(572)

BASt. (2011). Ausführungshinweise zum Leitfaden zum Arbeitsstellenmanagement auf Bundesautobahnen. Bundesanstalt für Straßenwesen. Version Maj 2011.

Benekohal, R. F., Kaja-Mohideen, A., \& Chitturi, M. V. (2003). Evaluation of Construction Work Zone Operational Issues: Capacity, Queue, and Delay. ITRC FR 00/01-4, Illinois Transportation Research Center, Champaign, IL.

Benekohal, R. F., Ramezani, H., \& Avrenli, K. A. (2010). Queue and User's Cost in Highway Work Zones. University of Illinois at Urbana Champaign, Research Report ICT-10-075. A report of A Model for Capacity Reduction at Roadwork Zone P. Str"omgren and J. Olstam 255 the findings of ICT-R27-33 Queue and Users' Costs in Highway Work Zones, Illinois Center for Transportation.

Bowdin, G., O'Toole, W., Allen, J., Harris, R., \& McDonnell, I. (2006). Events Management. Routledge. https://doi.org/10.4324/9780080457154

Chitturi, M. V., \& Benekohal, R. F. (2005). Effect of Lane Width on Speed of Cars and Heavy Vehicles in Work Zones. Transportation Research Record, 1920(1), 41-48. https://doi.org/10.1177/0361198105192000105

Crompton, J. L. (1995). Economic Impact Analysis of Sports Facilities and Events: Eleven Sources of Misapplication. Journal of Sport Management, 9(1), 14-35. https://doi.org/10.1123/jsm.9.1.14

Deccio, C., \& Baloglu, S. (2002). Nonhost Community Resident Reactions to the 2002 Winter Olympics: The Spillover Impacts. Journal of Travel Research, 41(1), 46-56. https://doi.org/10.1177/0047287502041001006 
Duivenvoorden, K. (2010). The Relationship Between Traffic Volume and Road Safety on the Secondary Road Network: A Literature Review. D-2010-2. SWOV Institute for Road Safety Research, Leidschendam.

FHWA. (2003). Managing Travel for Planned Special Events. Washington, DC: Federal Highway Administration.

Godley, S. T., Triggs, T. J., \& Fildes, B. N. (2004). Perceptual Lane Width, Wide Perceptual Road Center Markings and Driving Speeds. Ergonomics, 47(3), 237-256. https://doi.org/10.1080/00140130310001629711

Haragos, I. M., Holban, S., \& Cernazanu-Glavan, C. (2014). Determination of Quality Factor Used in Road Traffic. An Experimental Study. In 2014 IEEE 12th I ternational Symposium on Applied Machine Intelligence and Informatics (SAMI). https://doi.org/10.1109/SAMI.2014.6822390

Hogema, J. A., \& Brouwer, R. F. T. (1999). Inschatting van gedragseffecten van dynamische rijbaanindelingen. Soesterberg: TNO Technische Menskunde.

Karim, A., \& Adeli, H. (2003). Radial Basis Function Neural Network for Work Zone Capacity and Queue Estimation. Journal of Transportation Engineering, 129(5), 494-503.

https://doi.org/10.1061/(ASCE)0733-947X(2003)129:5(494)

Kwoczek, S., Di Martino, S., \& Nejdl, W. (2014). Predicting and Visualizing Traffic Congestion in the Presence of Planned Special Events. Journal of Visual Languages and Computing, 25(6), 973-980. https://doi.org/10.1016/j. jvlc.2014.10.028

Leilei, D., Jin-Gang, G., Zheng-Liang, S., \& Hong-Tong, Q. (2012). Study on Traffic Organization and Management Strategies for Large Special Events. In International Conference on System Science and Engineering (ICSSE) (pp. 432-436). https://doi.org/10.1109/ICSSE.2012.6257222

Lithuanian Official Statistics Portal. (n. d.). Available https://www.stat.gov.lt/en [Accessed: 10 February 2020].

Marchesini, P., \& Weijermars, W. (2010). The Relationship Between Road Safety and Congestion on Motorways. SWOV Inst. Road Saf. Res.

Maze, T., \& Bortle, M. (2005). Optimizing Work Zone Road Closure Capacity. Ames, Iowa, United Stated of America: Center for Transportation Research and Education Iowa State University.

Ortiz, L. A. (2014). Highway Work Zone Capacity Estimation Using Field Data From Kansas (Doctoral dissertation, Kansas State University).

Rietveld, P., \& Shefer, D. (1994). Congestion and Safety on Highways: Towards an Analytical Model. In Proceedings of the Third International Conference on Safety and the Environment in the 21st Century.

Skrodenis, D. (2019). Road Traffic Management During Special Events. In A. Varhelyi, V. Žuraulis, O. Prentkovskis (Eds.), Vision Zero for Sustainable Road Safety in Baltic Sea Region (pp. 104-109).

https://doi.org/10.1007/978-3-030-22375-5

Strömgren, P., \& Olstam, J. (2016). A Model for Capacity Reduction at Roadwork Zone. Transportation Research Procedia, 15, 245-256.

https://doi.org/10.1016/j.trpro.2016.06.021 
Trafikverket. (2014). Kapitel 2 Motorvägar. In TRVMB Kapacitet och

Traffic Management Solutions framkomlighetseffekter - Trafikverkets metodbeskrivning för beräkning av kapacitet och framkomlighetseffekter I vägtrafikanläggningar. TRV 2013:64343, Borlänge, Sweden.

at Roadwork Zones

During Planned

Special Events

Trafikverket. (2015). Effektsamband för vägtransportsystemet, Bygga om eller bygga nytt. Version 2015-04-01. Borlänge, Sweden.

Transportation Research Board. (2016). Freeway and Highway Segments: Supplemental. In Highway Capacity Manual. A Guide for Multimodal Mobility Analysis (6th ed.). Washington D.C.: Transportation Research Board.

Ullman, G. L., Porter, R. J., \& Karkee, G. J. (2009). Monitoring Work Zone Safety and Mobility Impacts in Texas. Texas Transportation Institute, The Texas A\&M University System.

Vejdirektoratet. (2010). Vejregel, Trafikteknik, Kapacitet og Serviceniveau.

Weinspach, K. (1988). Verkehrssicherheit und Verkehrsablauf im Bereich von Baustellen auf Betriebsstrecken der Bundesautobahnen, Strasse und Autobahn, 257-265. 